\title{
Injury prevention attitudes and awareness in New Zealand
}

\author{
R Hooper, C A Coggan, B Adams
}

\begin{abstract}
Objectives: This study was designed to obtain New Zealand data on beliefs related to a broad spectrum of injuries and their prevention.

Methods: A cross sectional phone survey was conducted of approximately 400 randomly selected households from each of 13 territorial local authorities across New Zealand, giving a total of 5282 . Respondents were asked questions on awareness and attitudes to injury prevention, ownership and use of safety equipment, safety behaviours, and incidence of self reported injury.

Results: $84 \%$ agreed with the statement that "Most injuries are preventable" and $91 \%$ rated their homes as "very safe" or "reasonably safe". A high proportion of homes had smoke alarms (81\%) and first aid kits $(81 \%)$, and more than half $(56 \%)$ had turned down the temperature of their hot water to $55^{\circ} \mathrm{C}$ or lower. However, less than half of the respondents said that they practised the other safety behaviours. Significant associations were found between the practise of safety behaviours and respondents' home safety ratings. There was a significant association between home safety ratings and the incidence of injury occurring in all settings $(p<0.0001)$, however there was no discernable association between home safety ratings and injury occurring in the home.

Conclusions: Although this survey found that most respondents believed that injuries are preventable and considered their homes to be safe, the public need to be further encouraged to adopt common safety practices and behaviours in the home.
\end{abstract}

See end of article for authors' affiliations

\section{Correspondence to:} Associate Professor Carolyn Coggan, Injury Prevention Research Centre, University of Auckland, Private Bag 92019, Auckland, New Zealand;

c.coggan@auckland.ac.nz njury is a leading cause of premature death and disability in New Zealand. ${ }^{1}$ On average, injuries result in approximately 1700 deaths and 42000 hospitalisations per year. ${ }^{2}$ The social and economic costs of injury are also high. In 2000/01 1.4 million claims for injury were accepted by the Accident Compensation Corporation. ${ }^{3}$ The overall social and economic cost of injury is estimated to be \$6-7 billion per year, yet many injuries and their consequences are preventable. ${ }^{4}$

Although injury rates in New Zealand have declined over the past decade, ${ }^{5}$ further reductions are possible and desirable as New Zealand compares poorly with other Organisation for Economic Co-Operation and Development countries in terms of injury and disability. ${ }^{6}$ For injuries to be prevented it is necessary to address a variety of behavioural, environmental, and social factors. Research evidence from a wide range of international studies has generally found that people believe that there is nothing you can do to prevent injuries-they just happen. ${ }^{7}$ Therefore raising awareness about injuries so that they are seen as preventable rather than an inevitable and unavoidable part of life seems necessary. While it is generally accepted that safer environments to support injury prevention activities are required, there is also clearly support in the literature for studying beliefs in relation to health behaviours (including injuries). For example, Wilde and Ackersviller found that people drive (more) carefully if they believe that car crashes are caused by human behaviour rather than fate, luck, or chance. ${ }^{8}$

Several researchers have conducted large sample surveys on the incidence of injury in New Zealand ${ }^{9}{ }^{10}$ and there have also been a number of international surveys reporting on safety behaviours and attitudes to injury prevention. ${ }^{11-15}$ However, we are unaware of international or national large scale surveys that have been conducted on knowledge, attitudes, behaviours, and incidence of a wide range of injuries across all age groups, the settings in which injuries occur, and how knowledge, attitudes, and behaviours may differ according to age, gender, and ethnicity. This study was designed to provide such data for New Zealand.

\section{METHODS}

This study reports on findings from a baseline survey that was designed as part of an on-going evaluation of injury prevention programmes being implemented in 13 regions of New Zealand. As the results from the baseline survey will be compared to findings from a future follow up survey, a sample of 400 households per region was required to provide sufficient power to detect differences between the baseline and follow up surveys. Hence a survey of approximately 400 randomly selected households from each of 13 different regions across New Zealand was conducted, giving a total sample of 5282. The survey was conducted between September and November 2001, using a computer assisted telephone interviewing system. Interviewers asked to speak to the person in the household who had the next birthday, and who was at least 18 years of age. Up to eight call backs were made to each household. The response rate was $65 \%$.

Attitudes were measured by asking respondents to rate on a five point scale (strongly agree, somewhat agree, neither disagree or agree, somewhat disagree, and strongly disagree) how they felt about a list of statements regarding the preventability of injuries. In addition, respondents were asked to rate the safety of the inside of their home on a four point scale (very safe, reasonably safe, needs improving, very unsafe).

Safety practices were measured by asking a series of questions to identify the safety items or hazards present in the home. These questions were based on information relating to preventing injuries in the home. ${ }^{16}$ Questions that pertained to child safety were only asked of those who reported that they were responsible for looking after children (0-14 years) in the previous 12 months. Responses were recorded as "yes", "no", or "some", and for all questions respondents also had the option of choosing "not applicable".

Information on the incidence of injury was obtained by asking respondents to list all injuries sustained by household members within the previous 12 months that required treatment from a medical doctor. Demographic information 


\begin{tabular}{ll}
$\begin{array}{l}\text { Table } 1 \text { Demographic characteristics } \\
\text { of respondents }\end{array}$ \\
\hline Demographic characteristic & No (\%) \\
\hline Gender & \\
Female & $3041(57.6)$ \\
Male & $2241(42.4)$ \\
Age group & \\
18-24 & $436(8.3)$ \\
$25-44$ & $2198(41.6)$ \\
$45-64$ & $1708(32.3)$ \\
$65+$ & $931(17.6)$ \\
Refused & $9(0.2)$ \\
Ethnicity & \\
Pakeha & $4303(81.5)$ \\
Maori & $525(9.9)$ \\
Asian & $87(1.6)$ \\
Pacific & $54(1.0)$ \\
Other & $298(5.6)$ \\
Refused & $15(0.3)$ \\
Household income per annum (\$NZ) \\
< \$25000 \\
\$25001-60000 & $1127(21.3)$ \\
\$60001-100000 & $2093(39.6)$ \\
$>\$ 100000$ & $1174(22.2)$ \\
Refused/don't know & $460(8.7)$ \\
\hline & $428(8.1)$ \\
\hline & \\
&
\end{tabular}

and circumstances of the injury were recorded for each incident. Injuries were recorded as occurring "in the home" if they occurred at the respondent's home or someone else's home.

All data were analysed using SAS version 8.1 for Windows. For nominal data, $\chi^{2}$ tests were used to test the alternative hypothesis of heterogeneity in the distribution of responses across the rows. For cases where both the row and column variables were ordinal, Mantel-Haenszel $\chi^{2}$ tests were used to test the alternative hypothesis of linear association between the rows and columns. All analyses were adjusted for regional effects. As multiple significance tests were carried out, the level of significance was set at $\alpha=0.001 ; \chi^{2}$ tests were used to compare the sample demographics to 1996 census data (Statistics New Zealand, 2002) for the regions sampled.

Due to some categories having small numbers, for analysis purposes the responses to the attitude questions were dichotomised into those who agreed (either strongly or somewhat) versus all other non-missing responses. Similarly, the safety practice variables were dichotomised as "yes" versus "no" and "some" combined.

\section{RESULTS}

The demographic characteristics of the sample are shown in table 1 . Females accounted for $57.6 \%$ of the respondents and although this was slightly higher than the percentage of females reported by census data (51.3\%), the gender distributions did not differ significantly $(\mathrm{p}=0.19)$. With regard to the size of the households sampled, $19.5 \%$ were single occupant households and this did not differ significantly $(\mathrm{p}=0.66)$ from the makeup of households in the census $(21.3 \%$ single occupant households). The age structure of the people in the households sampled was compared to census data and no significant differences were found.

\section{Attitudes}

As shown by fig 1, 83.9\% (99.9\% confidence interval (CI) $82.3 \%$ to $85.6 \%$ ) agreed strongly or somewhat that "most injuries are preventable". When this question was then analysed by particular types of injury, injuries occurring in the home were seen as most preventable $(90.8 \%$ in agreement, $99.9 \%$ CI $89.5 \%$ to $92.1 \%)$, while sporting injuries were regarded as least preventable (58.3\% in agreement, $99.9 \%$ CI $56.0 \%$ to $60.5 \%$ ).

As shown in table 2, males were significantly more likely to agree that most violence is preventable $(p<0.0001)$, but less likely to agree that most sports injuries are preventable $(\mathrm{p}<0.0001)$.

Significant age group trends were detected for all of the attitude questions except for injuries occurring in the home. Table 2 shows that people aged $65+$ were consistently least likely to agree with each of the injury prevention statements.

There were also significant ethnic differences for the statements concerning the preventability of sports injuries $(p<0.0001)$, and violence $(p=0.001)$. Pacific people were most likely to agree that most sports injuries are preventable; and Pacific and Maori were most likely to agree that most violence is preventable.

Significant household income trends were detected for statements regarding the preventability of all injuries $(p<0.0001)$, work related injuries $(p<0.0001)$, home injuries $(p<0.0001)$, and violence $(p<0.0001)$. For each of these statements, those with incomes of less than \$25000 per annum were least likely to agree that most injuries are preventable.

\section{Awareness}

As shown in table 3,91.4\% rated their homes as either reasonably safe or very safe. Only $0.5 \%$ said that their home was very unsafe.

The distribution of home safety ratings differed significantly by gender $(p<0.0001)$, with females more likely to report that the inside of their home was very safe (table 3 ). Home safety ratings also differed significantly by age group $(p<0.0001)$, with the percentage of people who rated their home as very safe increasing with increasing age.

Significant differences in the distribution of safety ratings were also observed by ethnicity $(\mathrm{p}<0.0001)$, with Pacific peoples least likely to rate their houses as very safe. Safety ratings responses also differed significantly by levels of household

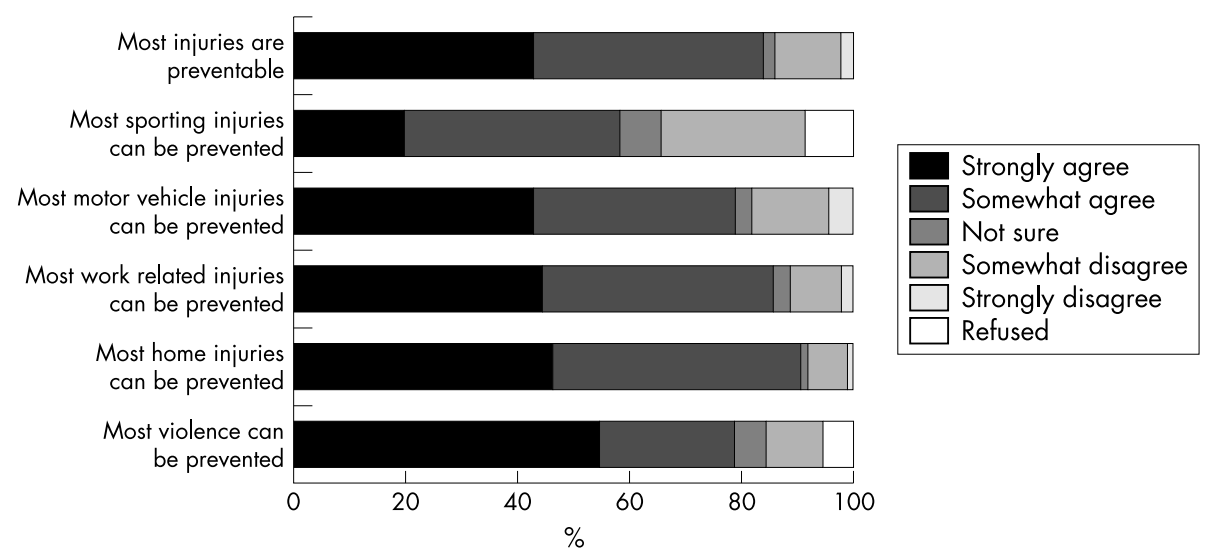

Figure 1 Attitudes to injury prevention. 


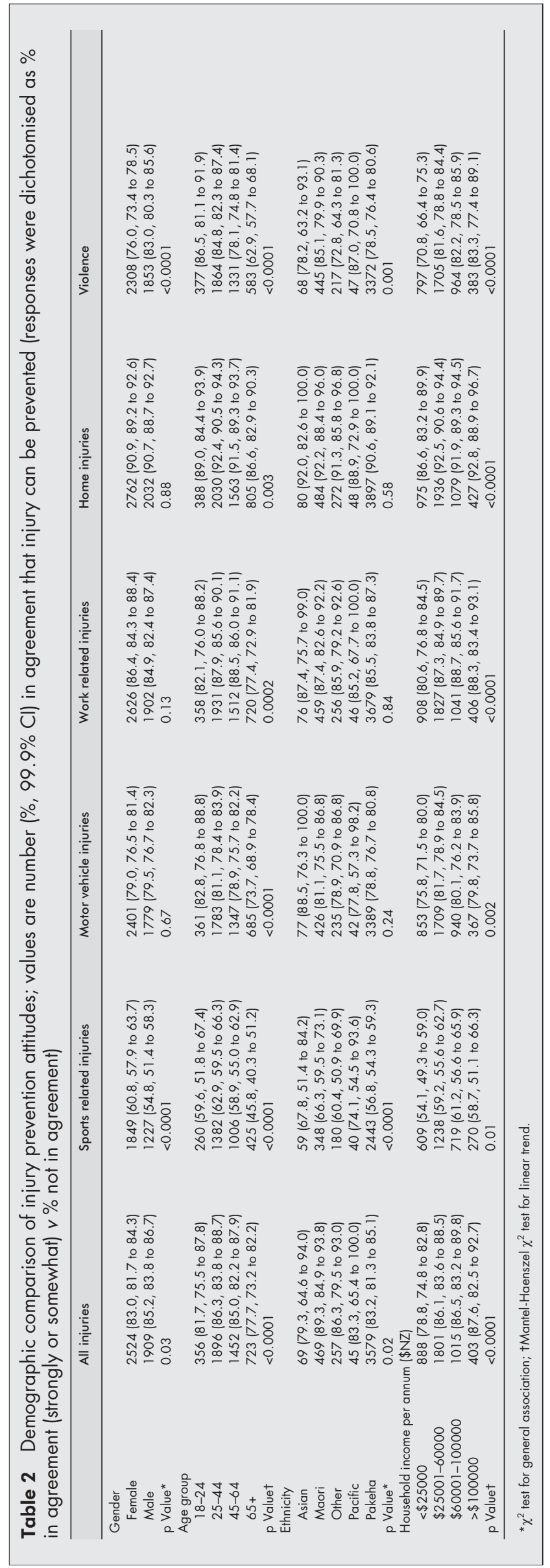

income $(\mathrm{p}<0.0001)$. Respondents living in households where the annual income was less than \$25000 were most likely to rate their homes as very safe.

\section{Safety practices}

Table 4 shows that the majority of homes had smoke alarms $(80.5 \%)$ and first aid kits $(80.7 \%)$. In addition, more than half $(55.7 \%)$ of the respondents reported that they had lowered their hot water temperature to $55^{\circ} \mathrm{C}$ or lower. However, for all the other safety questions only between a third and a half of the respondents reported that the other safety features were present.

The self reported home safety ratings were compared to the safety features that were reported to be present. The results from table 4 show that for all safety items/features (with the exception of stair guards/gates, heater guards, and the lowering of hot water temperature) the test for linear trend was significant, with the proportion of respondents who had the safety feature tending to increase as the safety rating of the home increased from "very unsafe" to "very safe".

\section{Comparison of home safety ratings with injury} incidence

Overall $41.4 \%$ (99.9\% CI $39.2 \%$ to $43.6 \%$ ) reported that someone in their household had been treated by a doctor for an injury occurring within the last 12 months. When the injuries were restricted to those occurring in the home only, 15.3\% $(99.9 \%$ CI $13.7 \%$ to $16.9 \%)$ reported an injury.

Home safety ratings were compared to the incidence of self reported injury. For injuries occurring in the home, there was no significant trend $(\mathrm{p}=0.08)$ by home safety rating. However, for injuries occurring at all locations, a significant trend was detected by home safety rating $(\mathrm{p}<0.0001)$. As shown by table 5 , the incidence of injury increased as the self rating of home safety decreased from "very safe" to "very unsafe".

\section{DISCUSSION}

Our findings indicate that the majority of those interviewed believed that most injuries are preventable. Although this is encouraging for injury prevention professionals and indicates that many of the injury prevention campaigns may be affecting public attitudes, such findings may also hinder future efforts to promote safety. The finding that many people viewed sporting injuries as least preventable provides opportunities to raise awareness among an important target audience. It may be that people are not sufficiently aware of the appropriate safety steps and equipment that can be used to prevent sporting injuries. It could also be a reflection of the strong rugby culture in New Zealand, and the high rates of injury associated with this sport. ${ }^{17}$

There may be several explanations for the finding that older respondents were less likely to agree that injuries are preventable. It is possible that older people may feel more vulnerable to injury as they grow older and frailer, particularly when compounded with other health problems. There may also be a generational effect, whereby older people have not grown up with the injury prevention messages that younger people have been exposed to in more recent times. ${ }^{18}$ The finding that respondents in the lowest income bracket were least likely to believe that injuries are preventable may be due to the fact that for low income households, many safety items (such as stair gates and safety glass) are a luxury that they simply cannot afford. These findings may be useful in terms of targeting particular demographic groups for injury prevention initiatives.

It was encouraging to discover that more than $90 \%$ of the respondents rated their homes as "very safe" or "reasonably safe". However, the finding that older respondents were most likely to rate their homes as safe contradicts the earlier finding 


\begin{tabular}{|c|c|c|c|c|c|}
\hline $\begin{array}{l}\text { Demographic } \\
\text { characteristic }\end{array}$ & $\begin{array}{l}\text { No (\%) who } \\
\text { said very safe }\end{array}$ & $\begin{array}{l}\text { No }(\%) \text { who said } \\
\text { reasonably safe }\end{array}$ & $\begin{array}{l}\text { No (\%) who said } \\
\text { needs improving }\end{array}$ & $\begin{array}{l}\text { No }(\%) \text { who said } \\
\text { very unsafe }\end{array}$ & $\mathrm{p}$ Value \\
\hline \multicolumn{6}{|l|}{ Gender } \\
\hline Female & 1110 (36.5) & 1686 (55.5) & $225(7.4)$ & $17(0.6)$ & \multirow[t]{2}{*}{$<0.0001$ * } \\
\hline Male & $700(31.3)$ & $1330(59.4)$ & $198(8.9)$ & $10(0.5)$ & \\
\hline \multicolumn{6}{|l|}{ Age group } \\
\hline $18-24$ & $98(22.5)$ & $275(63.1)$ & $57(13.1)$ & $6(1.4)$ & \multirow[t]{4}{*}{$<0.0001 \dagger$} \\
\hline $25-44$ & $591(26.9)$ & $1346(61.3)$ & $244(11.1)$ & $14(0.6)$ & \\
\hline $45-64$ & $634(37.2)$ & $961(56.3)$ & $105(6.2)$ & $6(0.4)$ & \\
\hline $65+$ & $483(51.9)$ & $430(46.2)$ & $16(1.7)$ & $1(0.1)$ & \\
\hline \multicolumn{6}{|l|}{ Ethnicity } \\
\hline Asian & $30(34.5)$ & 45 (51.7) & $11(12.6)$ & $1(1.2)$ & \multirow[t]{5}{*}{$<0.0001$ * } \\
\hline Maori & $172(32.8)$ & $279(53.2)$ & $66(12.6)$ & $7(1.3)$ & \\
\hline Other & $103(34.6)$ & $166(55.7)$ & $23(7.7)$ & $6(2.0)$ & \\
\hline Pacific & $15(27.8)$ & $33(61.1)$ & $6(11.1)$ & $0(0.0)$ & \\
\hline Pakeha & 1481 (34.5) & 2489 (57.9) & $316(7.4)$ & $12(0.3)$ & \\
\hline \multicolumn{6}{|c|}{ Household income per annum (\$NZ) } \\
\hline$<\$ 25000$ & $464(41.3)$ & $581(51.7)$ & $73(6.5)$ & $6(0.5)$ & \multirow[t]{6}{*}{$<0.0001 \dagger$} \\
\hline$\$ 25001-60000$ & $658(31.5)$ & $1221(58.4)$ & $200(9.6)$ & $12(0.6)$ & \\
\hline$\$ 60001-100000$ & $330(28.1)$ & $741(63.1)$ & $99(8.4)$ & $4(0.3)$ & \\
\hline$>\$ 100000$ & $166(36.1)$ & $268(58.3)$ & $25(5.4)$ & $1(0.2)$ & \\
\hline All respondents & $1810(34.3)$ & $3016(57.1)$ & $423(8.0)$ & $27(0.5)$ & \\
\hline Missing $=6(0.1)$ & & & & & \\
\hline
\end{tabular}

that older people were less likely to view injuries as being preventable. Similarly, the lower income households were most likely to rate their houses as safe, yet they also believed that injuries were less preventable compared with higher income brackets. These issues require further exploration.

We found that a high proportion of the respondents had smoke alarms and first aid kits, and that just over half had lowered the temperature of their hot water. There have been specific efforts in many parts of New Zealand to address these issues so this is encouraging. However, there is still room for improvement with regard to the other safety features in the home, with less than half of respondents reporting that they had any of the other safety features identified in this study.

Just over $40 \%$ of all respondents reported that someone in their household had sustained a medically treated injury in the previous year, and $15 \%$ of all respondents reported that a household member had sustained an injury at home. We did not find a significant association between the home safety rating and incidence of injury in the home. There are several possible explanations for this. It is possible that the safety items checklist did not cover some of the more common mechanisms of injuries such as falls, which have a diverse range of causes and account for a significant proportion of all medically treated injuries. ${ }^{19}$ Moreover, some of the questions we asked relate to relatively rare events, such as fires and electrocution. ${ }^{17}$ Also injuries recorded as happening at home could have occurred at someone else's home, thereby affecting the results. A significant association was found between home safety ratings and the incidence of all injuries. This suggests that households that practise safety in the home may have a strong safety culture, and implement safety measures outside of the home or vice versa.

\section{Limitations}

This study had a number of limitations. Firstly, as this was a cross sectional study, no inference can be made about causal relationships between variables. Secondly, as the survey relies on self reported safety practices and safety ratings, there may be issues concerning measurement validity. ${ }^{20}{ }^{21}$ Respondents may over-report injury prevention behaviours that are perceived to be desirable, resulting in social desirability bias. ${ }^{22}$ A study that compared the self reported incidence of seatbelt wearing with observational data found that self reported data overestimated the observed incidence of safety behaviours by up to $5 \% .{ }^{23}$ The validity of constructs reported on in this study may have been strengthened by the fact that respondents in this survey were allowed to choose between a range of ordinal responses (such as "Is your home very safe, reasonably safe, needs improving, very unsafe"), rather than being forced into choosing between two extremes. ${ }^{21}$ In addition, the significant associations between safety practices and safety ratings would indicate that people were consistent in the manner in which they answered these questions.

Some bias may also have been introduced by the use of a phone survey, as households without a telephone may differ demographically from those with one. ${ }^{24-26}$ However, only $4.3 \%$ of households in the regions sampled reported that they did not have access to a telephone in the 1996 census, ${ }^{27}$ and comparisons of key sample demographics with census data indicated that the households sampled were representative of the regions surveyed. It should also be recognised that while the questions asked in the survey generally applied to the household, the demographic information applies only to the person answering the survey.

It is also possible that this survey was subject to recall bias. Several other studies have found a decline in recall of injury events when comparing a 12 month recall period to shorter periods, thereby resulting in an underestimate of the annual injury rate. ${ }^{28-30}$ However, the interviewers read out a list of different injury mechanisms and this may have helped respondents to remember a greater number of injuries. The respondents may also have been less likely to recall less medically serious incidents of injury. ${ }^{26-28}$ It is also possible that respondents may not have been aware of all injury incidents for their household.

\section{IMPLICATIONS FOR PREVENTION}

One of the major strengths of this study is the survey's large sample. There have been few other studies in New Zealand that have obtained comprehensive injury related information from such a large and demographically diverse sample. These results provide a useful baseline measurement of attitudes to injury prevention and the practise of safety behaviours that can be further refined internationally or nationally.

The question remains that if the majority of our homes are reportedly "safe", then why are the rates of injury in New 


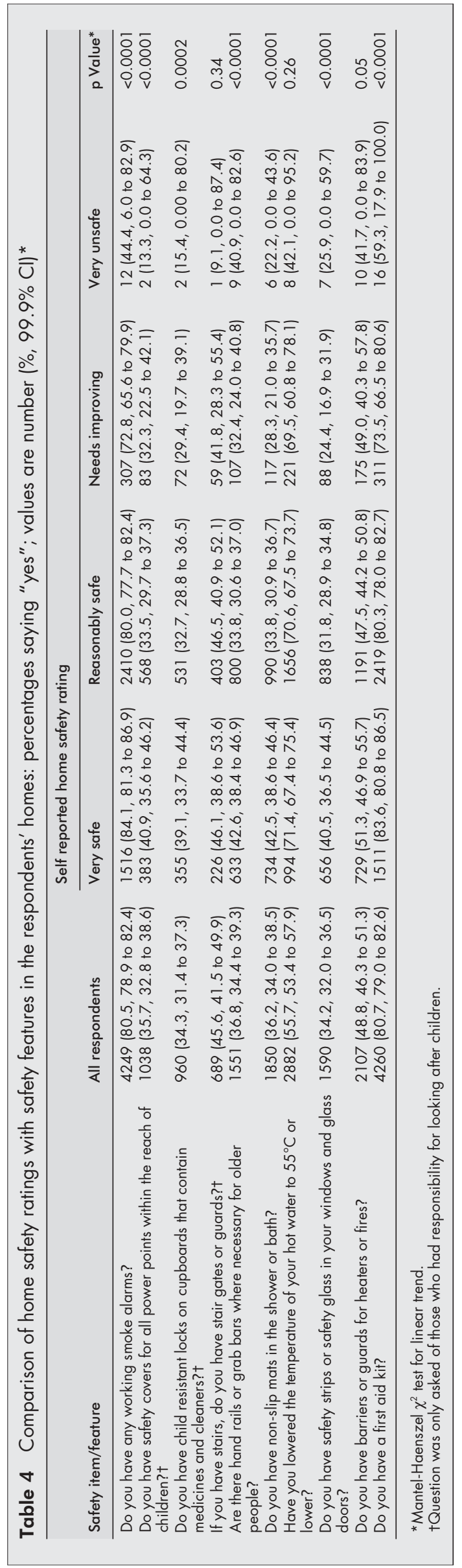

Table 5 Incidence of injury by rating of home safety; values are number $(\%, 99.9 \% \mathrm{Cl})$

\begin{tabular}{|c|c|c|}
\hline $\begin{array}{l}\text { Home safety } \\
\text { rating }\end{array}$ & $\begin{array}{l}\text { Households with an } \\
\text { injury occurring at home }\end{array}$ & $\begin{array}{l}\text { Households with any } \\
\text { injury }\end{array}$ \\
\hline $\begin{array}{l}\text { Very safe } \\
\text { Reasonably safe } \\
\text { Needs improving } \\
\text { Very unsafe } \\
\text { p Value* }\end{array}$ & $\begin{array}{l}250(13.8,11.1 \text { to } 16.5) \\
490(16.3,14.0 \text { to } 18.5) \\
65(15.4,9.5 \text { to } 21.2) \\
3(11.1,0.0 \text { to } 37.2) \\
0.08\end{array}$ & $\begin{array}{l}650(35.9,32.2 \text { to } 39.6) \\
1319(43.7,40.8 \text { to } 46.7) \\
198(46.8,38.8 \text { to } 54.8) \\
17(63.0,34.7 \text { to } 91.2) \\
<0.0001\end{array}$ \\
\hline
\end{tabular}

\section{Key points}

- Results for this large study provide a useful baseline measurement of attitudes to injury prevention.

- Respondents considered that injuries in the home were most preventable while sporting injuries were regarded as least preventable.

- A high proportion of homes had smoke alarms and first aid kits.

- There was a significant association between the practice of safety behaviours and respondents' home safety ratings.

- There was a significant association between home safety ratings and the incidence of injury occurring in all settings.

Zealand so high? It could be argued that while people's ratings of their home safety are accurate in terms of relative comparisons, it would be desirable to raise the proportion of the population who use common safety devices in the home. Further research is also needed into injuries such as falls in the home, to identify potential safety measures that could be promoted by the injury prevention community.

\section{ACKNOWLEDGEMENTS}

The Injury Prevention Research Centre wishes to acknowledge the funding support it receives from the Accident Compensation Corporation, the Health Research Council of New Zealand, and the Ministry of Health.

\section{Authors' affiliations}

R Hooper, C A Coggan, Injury Prevention Research Centre, University of Auckland

B Adams, Accident Compensation Corporation, Wellington

\section{REFERENCES}

1 Ministry of Health. The burden of disease and injury in New Zealand. Wellington: Ministry of Health, 2001.

2 Coggan C, Langley J, Dawe $M$, et al. A proposed strategy for vote health funding for injury prevention. Auckland: Injury Prevention Research Centre, 2000.

3 Accident Compensation Corporation. ACC injury statistics 2001. Wellington: ACC, 2001.

4 Accident Compensation Corporation. Draft injury prevention strategy. Wellington: ACC, 2002.

5 Injury Prevention Research Unit. Statistics [online] (http:// www.otago.ac.nz/Web_menus/Dept_Homepages/IPRU/Statistics/ FatQ.html). Accessed May 2002

6 UNICEF. A league table of child deaths by injury in rich nations. Innocenti report card No 2. Florence: UNICEF Innocenti Research Centre, 2001.

7 Girasek D. Public beliefs about the preventability of unintentional injury deaths. Accid Anal Prev 2001;33:455-65.

8 Wilde G, Ackersviller M. Accident journalism and traffic safety education: a three- phase investigation of accident reporting in the Canadian daily press (prepared for Traffic Safety). Ottawa: Transport Canada, 1981

9 Ameratunga $S$, Norton R, Whitlock $G$, et al. The New Zealand blood donors' health study: baseline findings of a large prospective cohort study of injury. Inj Prev 2002;8:66-9.

10 Ministry of Health. Taking the pulse. The 1996/97 New Zealand Health Survey. Wellington: Ministry of Health, 1999.

11 Bolen J, Sacks J, Bland S. Injury prevention behaviours: a report card for the nation, 1995. Preventative Medicine 1999;29:195-201. 
12 Hendricks C, Reichert A. Parents' self-reported behaviours related to health and safety of very young children. J Sch Health 1996;66:247-51.

13 Eichelberger $M$, Gotschall C, Feely $\mathrm{H}$, et al. Parental attitudes and knowledge of child safety. A national survey. Am J Dis Child 1990;144:714-20.

14 Peterson L, Farmer J, Kashani J. Parental injury prevention endeavors: a function of health beliefs? Health Psychol 1990:9:177-91.

15 Hapgood R, Kendrick D, Marsh P. Do self reported safety behaviours predict childhood unintentional injury? Inj Prev 2001;7:14-17.

16 Towner E, Ward H. Prevention of injuries to children and young people: the way ahead for the UK. Inj Prev 1998;4(suppl):S17-25.

17 Simpson J, Chalmers D, Thomson C. Evaluating tackling rugby injury: the pilot phase for monitoring injury. Aust N Z J Public Health 1999;23:86-8

18 Bonnie R, Fulco C, Liverman C. Reducing the burden of injury. Washington: National Academy Press, 1999.

19 UK Dept of Trade and Industry. Government Consumer Accident Data and Safety. Home accident surveillance system including leisure activities, 21 st annual report 1997 data. London: Department of Trade and Industry, 1998: 35.

20 Scott I. You can't believe all that you're told: the issue of unvalidated questionnaires. Inj Prev 1997;3:5-6.

21 Mickalide A. Threats to measurement validity in self reported data can be overcome. Inj Prev 1997;3:7-8.
22 Vinten E. Taking the threat out of threatening questions. J $R$ Soc Health 1998;118:10-14

23 Nelson D. Validity of self reported data on injury prevention behavior: lessons from observational and self reported surveys of safety belt usage in the US. Inj Prev 1996;2:67-9.

24 Corey CR, Freeman HE. Use of telephone interviewing in health care research. Health Serv Res 1990;25(1 pt 1):129-44.

25 Donovan RJ, Holman CD, Corti B, et al. Face-to-face household interviews versus telephone interviews for health surveys. Aust N Z J Public Health 1997:21:134-40.

26 Smith W, Mitchell P, Attebo K, et al. Selection bias from sampling frames: telephone directory and electoral roll compared to door-to-door population census: results from the Blue Mountains Eye Study. Aust N Z J Public Health 1997;21:127-33.

27 Statistics New Zealand. Standard regional tables (1996) [online] (http://www.stats.govt.nz/domino/external/web/ExtraPages.nsf/ htmldocs/Standard+Regional+ Tables+Census+1996+-+Map). Accessed June 2002.

28 Jenkins $\mathbf{P}$, Earle-Richardson G, Tucker Slingerland D, et al. Time dependent memory decay. Am J Ind Med 2002;41:98-101.

29 Harel $Y$, Overpeck $M$, Jones $D$, et al. The effects of recall on estimating annual nonfatal injury rates for children and adolescents. Am J Public Health 1994:84:599-605.

30 Landen D, Hendricks S. Effect of recall on reporting at-work injuries. Public Health Rep 1995;110:350-4.

\section{LACUNAE}

The Arizona Republic reported in October that Native Americans are living in danger. For most Americans the leading cause of death is heart disease, then cancer. For Navajos, it's accidents. The unintentional injury, or accidental, death rate for Navajos is 138.5 per 100000 compared with 30.1 for all races. It's the highest of all Indians (contributed by Ian Scott).

\section{Traffic to be biggest killer in two decades}

Traffic accidents are set to become one of the world's biggest killers in the next two decades, with pedestrians making up the largest number of victims, the leader of a United Nations sponsored research body said. Such accidents are currently the ninth leading cause of death globally, Dr Adnan Hyder, a founding member of the Road Traffic Injury Research Network, said Wednesday. The network is funded by the World Health Organization.

The most recent United Nations statistics show that almost 1.2 million people were killed on the world's roads in 1998, Hyder said. In 1998 more than 1 million of the world's road accident victims were in Africa, Asia, South and Central America, and regions like the former Soviet Union.

By 2020, road accidents will be the third leading cause of death, behind heart disease and deaths linked to mental illness, Hyder said. The WHO definition of deaths linked to mental illness includes degenerative conditions like Alzheimer's disease, suicides by people suffering from depression, and alcohol abuse. Governments-especially in poor countries—must find new ways to reduce the carnage, he said.

Most of the accidents occur in developing countries where Western-style traffic regulations are largely ineffective because they are rarely enforced or because people and vehicles have to share the same busy roads. "Two thirds of the people who die are pedestrians", Hyder told reporters. "People who will never own a car in their life are at the greatest risk".

Most road safety studies are produced in rich countries and their lessons may not be appropriate for the developing world, he said. Boosting law enforcement-clamping down on people who fail to wear a seatbelt, for example - can be much less effective than "separating the space", so pedestrians and cyclists do not have to travel alongside cars or buses, he said (Associated Press, August 2002, contributed by Peter Jacobsen). 